\title{
The Role of the Electron Density and Magnetic Couplings on the NICS profiles of [2.2]Paracyclophane and Related Species
}

Jordi Poater, Josep M. Bofill, Pere Alemany, and Miquel Solà

\section{SUPPORTING INFORMATION}

- Benzene Cartesian coordinates $\quad$ S2

- para-Xylene Cartesian coordinates $\quad$ S2

- Benzene-dimer Cartesian coordinates S2

- [2.2]Paracyclophane Cartesian coordinates S3 
- Benzene (MP2=-231.519173):

$\begin{array}{cccccc}1 & 6 & 0 & 0.000000 & 1.398726 & 0.000000 \\ 2 & 6 & 0 & 1.211332 & 0.699363 & 0.000000 \\ 3 & 6 & 0 & 1.211332 & -0.699363 & 0.000000 \\ 4 & 6 & 0 & 0.000000 & -1.398726 & 0.000000 \\ 5 & 6 & 0 & -1.211332 & -0.699363 & 0.000000 \\ 6 & 6 & 0 & -1.211332 & 0.699363 & 0.000000 \\ 7 & 1 & 0 & 0.000000 & 2.481971 & 0.000000 \\ 8 & 1 & 0 & 2.149450 & 1.240985 & 0.000000 \\ 9 & 1 & 0 & 2.149450 & -1.240985 & 0.000000 \\ 10 & 1 & 0 & 0.000000 & -2.481971 & 0.000000 \\ 11 & 1 & 0 & -2.149450 & -1.240985 & 0.000000 \\ 12 & 1 & 0 & -2.149450 & 1.240985 & 0.000000\end{array}$

- para-Xylene (MP2=-309.895086):

$\begin{array}{cccrrc}1 & 6 & 0 & 1.200988 & 0.698795 & -0.012242 \\ 2 & 6 & 0 & 1.200988 & -0.698795 & -0.012242 \\ 3 & 6 & 0 & 0.000000 & -1.421795 & -0.010627 \\ 4 & 6 & 0 & -1.200988 & -0.698795 & -0.012242 \\ 5 & 6 & 0 & -1.200988 & 0.698795 & -0.012242 \\ 6 & 6 & 0 & 0.000000 & 1.421795 & -0.010627 \\ 7 & 1 & 0 & 2.145695 & 1.232761 & -0.021156 \\ 8 & 1 & 0 & 2.145695 & -1.232761 & -0.021156 \\ 9 & 1 & 0 & -2.145695 & -1.232761 & -0.021156 \\ 10 & 1 & 0 & -2.145695 & 1.232761 & -0.021156 \\ 11 & 6 & 0 & 0.000000 & -2.928221 & 0.024732 \\ 12 & 1 & 0 & 0.000000 & -3.299063 & 1.051739 \\ 13 & 1 & 0 & -0.882525 & -3.329829 & -0.473580 \\ 14 & 1 & 0 & 0.882525 & -3.329829 & -0.473580 \\ 15 & 6 & 0 & 0.000000 & 2.928221 & 0.024732 \\ 16 & 1 & 0 & -0.882525 & 3.329829 & -0.473580 \\ 17 & 1 & 0 & 0.000000 & 3.299063 & 1.051739 \\ 18 & 1 & 0 & 0.882525 & 3.329829 & -0.473580\end{array}$

- Benzene-dimer (MP2=-463.0447155):

$\begin{array}{cccccc}1 & 6 & 0 & 0.000000 & 1.398517 & 1.921522 \\ 2 & 6 & 0 & 1.211151 & 0.699259 & 1.921522 \\ 3 & 6 & 0 & 1.211151 & -0.699259 & 1.921522 \\ 4 & 6 & 0 & 0.000000 & -1.398517 & 1.921522 \\ 5 & 6 & 0 & -1.211151 & -0.699259 & 1.921522 \\ 6 & 6 & 0 & -1.211151 & 0.699259 & 1.921522 \\ 7 & 1 & 0 & 0.000000 & 2.482035 & 1.918958 \\ 8 & 1 & 0 & 2.149506 & 1.241018 & 1.918958 \\ 9 & 1 & 0 & 2.149506 & -1.241018 & 1.918958 \\ 10 & 1 & 0 & 0.000000 & -2.482035 & 1.918958 \\ 11 & 1 & 0 & -2.149506 & -1.241018 & 1.918958 \\ 12 & 1 & 0 & -2.149506 & 1.241018 & 1.918958\end{array}$




$\begin{array}{rrrrrr}13 & 6 & 0 & 0.000000 & 1.398517 & -1.921522 \\ 14 & 6 & 0 & 1.211151 & 0.699259 & -1.921522 \\ 15 & 6 & 0 & 1.211151 & -0.699259 & -1.921522 \\ 16 & 6 & 0 & 0.000000 & -1.398517 & -1.921522 \\ 17 & 6 & 0 & -1.211151 & -0.699259 & -1.921522 \\ 18 & 6 & 0 & -1.211151 & 0.699259 & -1.921522 \\ 19 & 1 & 0 & 0.000000 & 2.482035 & -1.918958 \\ 20 & 1 & 0 & 2.149506 & 1.241018 & -1.918958 \\ 21 & 1 & 0 & 2.149506 & -1.241018 & -1.918958 \\ 22 & 1 & 0 & 0.000000 & -2.482035 & -1.918958 \\ 23 & 1 & 0 & -2.149506 & -1.241018 & -1.918958 \\ 24 & 1 & 0 & -2.149506 & 1.241018 & -1.918958\end{array}$

- Paracyclophane (MP2=-617.3942518):

$\begin{array}{cccccc}1 & 6 & 0 & -1.410620 & 1.402330 & 0.042430 \\ 2 & 6 & 0 & -0.734440 & 1.564190 & -1.172140 \\ 3 & 6 & 0 & 0.657610 & 1.560670 & -1.212470 \\ 4 & 6 & 0 & 1.410620 & 1.402330 & -0.042430 \\ 5 & 6 & 0 & 0.734440 & 1.564190 & 1.172140 \\ 6 & 6 & 0 & -0.657610 & 1.560670 & 1.212470 \\ 7 & 6 & 0 & 2.792330 & 0.793960 & -0.097820 \\ 8 & 6 & 0 & 2.792330 & -0.793960 & 0.097820 \\ 9 & 6 & 0 & -1.410620 & -1.402330 & -0.042430 \\ 10 & 6 & 0 & -0.657610 & -1.560670 & -1.212470 \\ 11 & 6 & 0 & 0.734440 & -1.564190 & -1.172140 \\ 12 & 6 & 0 & 1.410620 & -1.402330 & 0.042430 \\ 13 & 6 & 0 & 0.657610 & -1.560670 & 1.212470 \\ 14 & 6 & 0 & -0.734440 & -1.564190 & 1.172140 \\ 15 & 6 & 0 & -2.792330 & 0.793960 & 0.097820 \\ 16 & 6 & 0 & -2.792330 & -0.793960 & -0.097820 \\ 17 & 1 & 0 & -1.292420 & 1.542740 & -2.106850 \\ 18 & 1 & 0 & 1.159130 & 1.535870 & -2.178560 \\ 19 & 1 & 0 & 1.292420 & 1.542740 & 2.106850 \\ 20 & 1 & 0 & -1.159130 & 1.535870 & 2.178560 \\ 21 & 1 & 0 & 3.445690 & 1.227360 & 0.668950 \\ 22 & 1 & 0 & 3.251110 & 1.021300 & -1.066870 \\ 23 & 1 & 0 & 3.251110 & -1.021300 & 1.066870 \\ 24 & 1 & 0 & 3.445690 & -1.227360 & -0.668950 \\ 25 & 1 & 0 & -1.159130 & -1.535870 & -2.178560 \\ 26 & 1 & 0 & 1.292420 & -1.542740 & -2.106850 \\ 27 & 1 & 0 & 1.159130 & -1.535870 & 2.178560 \\ 28 & 1 & 0 & -1.292420 & -1.542740 & 2.106850 \\ 29 & 1 & 0 & -3.445690 & 1.227360 & -0.668950 \\ 30 & 1 & 0 & -3.251110 & 1.021300 & 1.066870 \\ 31 & 1 & 0 & -3.251110 & -1.021300 & -1.066870 \\ 32 & 1 & 0 & -3.445690 & -1.227360 & 0.668950\end{array}$

